\title{
Strategic Policy Overreaction as a Risky Policy Investment
}

Moshe Maor

\section{(2) OpenEdition \\ Journals}

Electronic version

URL: http://journals.openedition.org/irpp/277

DOI: $10.4000 /$ irpp. 277

ISSN: 2706-6274

Publisher

International Public Policy Association

\section{Printed version}

Date of publication: 17 June 2019

Number of pages: $46-64$

ISSN: 2679-3873

\section{Electronic reference}

Moshe Maor, «Strategic Policy Overreaction as a Risky Policy Investment », International Review of Public Policy [Online], 1:1 | 2019, Online since 17 June 2019, connection on 05 October 2019. URL : http://journals.openedition.org/irpp/277 ; DOI : 10.4000/irpp.277

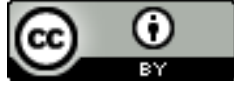




\section{Strategic Policy Overreaction as a Risky Policy Investment}

\section{Moshe Maor}

The Hebrew University of Jerusalem

\section{Abstract}

Policy overreaction is a policy that imposes objective and/or perceived social costs without producing offsetting objective and/or perceived benefits. It is therefore an objective fact and, at the same time, a matter of interpretation. Policy scholars tend to view this duality as a problematic ontological issue and to categorize such policies as errors of commission or omission. This article builds on (i)the aforementioned duality and (ii)a recent conceptual turn whereby this concept is re-entering the policy lexicon as a type of deliberate policy choice. This may be motivated by, among other factors, political executives' desire to pander to public opinion, appear informed to voters, and signal extremity. The article assigns specific policy overreaction responses to two dimensions: the scale of policy in terms of objective costs and benefits, and public perceptions of policy. The derived policy taxonomy highlights four distinct empirical categories, which are elaborated and exemplified here, as well as a set of hypotheses about differing patterns of politics and governance associated with the design of these policy choices. These distinctions should facilitate a more systematic empirical test of strategic policy overreaction as a risky policy investment.

\section{Keywords}

disproportionate policy, overreaction, rhetoric, doctrine, zero-tolerance policy, unlimited policy, torture, targeted killings, President Trump, governance 
What is the actual process of scientific observation in the field of public policy? Or, borrowing from Sherlock Holmes' discourse with Dr. Watson, what do policy scholars see and, more importantly, see but not observe when looking at policy processes? Policy scholars look at the policy landscape using a certain theory of the policy process and thus see punctuations, streams, garbage cans, feedback, advocacy coalitions, narratives, institutional arrangements, and other phenomena. At the same time, they see but do not observe systematic variations in policy overreaction, let alone patterns of strategic policy overreaction which may be motivated by, among other factors, political executives' desire to address disparities between voters' expectations and governments' actual policy capacity (e.g., Maor 2017a, 2017b, 2018a, forthcoming; Maor et al. 2017). One example of this is a government that has the capacity to solve a security problem in a cost-effective way within a month, while incurring minimal military and civilian casualties, yet the public demands a solution within mere days and will tolerate little or no loss of life. In such cases, because policy is not evaluated in a vacuum but rather vis-à-vis an information set comprised of cost-benefit analyses, situation evaluations and risk assessments, it may be possible to identify policy overreaction before the policy is implemented and in relation to what could happen.

Policy overreaction is defined as "policy that imposes objective and/or perceived social costs without producing offsetting objective and/or perceived benefits" (Maor 2012, 232) ${ }^{1}$. Objective cost-benefit analysis places a premium on science, statistics, and economics, and can be used to correct public complacency or hysteria (Sunstein 2018). Subjective cost-benefit arguments tend to represent an emotional, value-laden approach to policy issues. A policy decision is strategic when a government or equivalent authority makes a calculated decision to act in order to advance long-term goals. Evidence of strategic policy overreaction may be found, for instance, in cases of policy responses which are insensitive to the heterogeneity of the target audience or implementing agencies; policy responses to manufactured policy problems (i.e., when there is no need for government action); policy responses that violate fundamental precepts of the rule of law (e.g., acting with no legal basis); policy responses that proceed without cost-benefit analysis; and excessive policies which are implemented against the advice of senior officials which are based on cost-benefit analysis, risk assessment, and/or situation evaluation. Regarding policy responses to manufactured problems, suffice it to mention the 1942 internment of all American citizens of Japanese ancestry in camps although there was no evidence that Japanese Americans were involved in any clandestine activity at that time (Alford 2017, p. 35), or the cull of all pigs in Egypt during the swine flu crisis of 2009, even though not a single case of this disease, among either humans or pigs, had been reported in that country. Numerous actions by the U.S. executive branch, which violated fundamental precepts of the rule of law during the Cold War and the Nixon Presidency, have been discussed elsewhere (Alford 2017, pp. 33-55).

Policy overreaction is a common phenomenon, as the insight provided by punctuated equilibrium theory implies: namely, policy responses oscillate between periods of underreaction to the flow of information from the environment into the system and overreaction due to disproportionate information processing (Baumgartner and Jones 1993). It is therefore rather surprising that little attention has been devoted to the study of this phenomenon. One reason for this may revolve around the in-built fluidity in the concept of policy overreaction: it is an objective fact and, at the same time, a matter of interpretation. Other reasons may include the

1 - One manifestation of policy overreaction is the clear-cut concept of policy overinvestment which occurs "when government overinvests in a single policy instrument beyond its instrumental value in achieving a policy goal" (Jones et al. 2014, p. 149). 
obstacles in defining and measuring policy costs and benefits from the policymakers' viewpoint (e.g., "What policymakers feel to be a cost, observers may not so categorize, or vice versa" [Jervis 2017, p. 115]), the negative meaning of this concept due to the misallocation of scarce resources and the consequent undermining of societal welfare, and the common view that regards all overreactions as errors of commission or omission (e.g., Hogwood and Peters 1985; Walker and Malici 2011).

As reality overwhelms traditional policy theories, and as experience and the ordinary part ways, it is becoming increasingly clear that policy overreaction constitutes an extremely important phenomenon. Suffice it to mention the separation of children from their parents at the US border, disregarding the heterogeneity of this target audience as well as the traumatic effects of this policy on young children. The Trump administration defended the use of this policy, claiming that it is a deterrent against other potential immigrants, as well as a negotiating tool in the President's efforts to force Democrats to cave on his immigration demands. Thus, it could be considered a deliberate policy overreaction. In recent years, President Vladimir Putin, President Rodrigo Duterte, Prime Minister Binyamin Netanyahu, and many others have also pursued such policy responses, at the rhetorical and doctrinal levels, as well as on the ground. The phenomenon of populist-authoritarianism and its mass appeal as a style of governance (e.g., Norris and Inglehart 2018), as well as celebrity politicians behaving as celebrities rather than politicians (e.g., Marsh et al. 2010; Street 2018; Wheeler 2013; Wood et al. 2016), further emphasizes the importance of strategic policy overreactions in modern politics. Against this background, the present article endeavors to improve our understanding of variation within this type of overreaction.

Building on the premise that policy overreaction is an objective fact and, at the same time, a matter of interpretation, we assign specific policy overreaction responses to two dimensions: namely, the scale of policy in terms of objective costs and benefits, and public perceptions of policy. The derived policy taxonomy highlights four empirically distinct categories of strategic policy overreaction alternatives which, if successful, may confer on policymakers both tangible and intangible political benefits, among them increasing their capacity to exercise authority, influencing the policies of rivals, shaping the psychological environment within which policies are enacted, and garnering popular support amongst the general public or the base of political executives' support.

The first category includes zero-tolerance policies (e.g., zero-tolerance border enforcement policy; zero-tolerance crime policy; zero-tolerance policy for sexual harassment in government agencies) as well as unlimited policies (e.g., open border policy). Both are characterized by large scale overreaction (i.e., social costs considerably outweigh social benefits due to the policy's insensitivity to the heterogeneity of the target population and/or the implementing agencies), and large segments of the population perceive them as overreaction (e.g., due to disproportionalities in policy outcomes, such as the racial disproportionalities in the prison population).

The second category includes explicit overreaction rhetoric and doctrine as well as precision overreaction (e.g., targeted killings using invasive coercive measures; police stop and search policy). Both are characterized by small scale overreaction, but large segments of the population regard such policies as overreaction. Regarding the former sub-category, the cost of statements of intent is not incurred as they are made, but only later, if actors do not live up to them. Furthermore, the public perception of such policies as overreaction mainly results from the use of unconventional language, such as personal insults or sarcasm (e.g., Donald Trump's dire threats of conflagration aimed at Pyongyang). Concerning the latter sub-category, small-scale 
overreaction is facilitated by, for example, the relatively inexpensive lethal drone technology, while the perception of such policies as overreaction derives, for instance, from collateral damage to civilians and property, violations of sovereignty resulting from unauthorized entry into another state's territory, or ambiguity in the distinction between legitimate and illegitimate (human) targets.

The third category includes implicit overreaction rhetoric and doctrines (e.g., communication of statements of intent via informal diplomatic channels). These are characterized by small scale overreaction and viewed by large segments of the population as proportionate or underreaction. An example is the informal messages that the Israeli Prime Minister, Golda Meir, communicated to Egyptian President Anwar Sadat during the period 1970-1973, via the US as well as non-governmental actors, informing him that continuing the war of attrition would meet with a disproportionate response from the Israeli side ${ }^{2}$.

Finally, the fourth category is comprised of covert overreactions (e.g., US systematic torture and mass-surveillance programs). These are characterized by large scale overreaction (i.e., due to the cost of maintaining "black" sites for covert policy, developing and employing advanced technologies, developing modes of covert operations, concealing sites and operations, and so on) and are regarded by large segments of the population as a proportionate response and/or underreaction (e.g., due to the inherent secrecy of covert action and restrictions on the voicing of dissent by employees). Making these distinctions establishes a vocabulary for the description of strategic policy overreaction; clarifies some of the practical alternatives for employing such policy; and facilitates a more systematic empirical test of such responses.

The article is organized in the following way. We briefly discuss the perils of ignoring the phenomenon of strategic policy overreaction. We then review the relevant literature and elaborate on the proposed taxonomy. Subsequently, we present a set of hypotheses regarding differing patterns of politics and governance associated with the design of these policy choices. We conclude by discussing the challenges ahead and proposing avenues for future research.

\section{The Perils of Ignoring Strategic Policy Overreaction}

Ignoring the phenomenon of deliberate policy overreaction, and especially underestimating the political benefits that policymakers may reap from such a policy, has several consequences. These are relevant regardless of what causes the policy overreactions.

First, many policy scholars tend to see policy outcomes in objective cost-benefit terms, thereby paying little attention to or completely ignoring the ideational and symbolic aims of the policy (Schneider et al. 2014). This is because they largely tend to analyze the 'physical' dimension of policy (e.g., the number of public hospitals erected during a certain period), ignoring the fact that every policy has a symbolic component (i.e., a 'message' communicated to target populations and to policy actors at the policy sub-system level), and at times also a strategic component (i.e., strategic implications at the policy system level). For example, "Police stops convey powerful messages about citizenship and equality [...] [which are] translated into common stories about who is an equal member of a rule-governed society and who is subject to arbitrary surveillance and inquiry" (Epp 2014, 2). Consequently, policy scholars may miss the reduction of symbols/ideas to operational purposes.

Second, policy scholars tend to pay little attention to or completely ignore policies which are

2 - I would like to thank Uri Bar-Joseph for this example. 
based on (catastrophic) worst-case policy scenarios (e.g., Sunstein 2018, pp. 171-2). As a result, they may miss a possible general trend, according to which many policy solutions are increasingly viewed through the filter of worst-case scenario. Furthermore, if policymakers and government agencies are designed to think along a military or police model (i.e., prioritizing maximalist response over a proportionate one, while constantly assuming that the unanticipated all too often happens), policy scholars may miss the resulting shift in the relationships between policymakers and the general public.

Third, policy scholars tend to seek hard-boiled proofs for assessing policy outcomes; they are therefore great advocates of systems of performance indicators. This, in turn, leads to increased focus on operational aspects at different organizational levels and positions (politicians, top civil servants, middle managers, street-level bureaucrats, and actors outside state structures), at the expense of uncovering new ways of interpreting salient policy issues that may be developing among policymakers and the general public. For example, global and domestic threats, coupled with the rising number of people who are skeptical about politicians and political institutions, imply that policy overshooting is increasingly necessary to ensure that the public perceives a policy action as sufficient and politicians as competent, at least in the short-term. This neglect is akin to geography scholars ignoring the climate change in the Arctic that is re-shaping the global economy by opening shorter trade routes and extending shipping lanes through melting ice.

Relatedly, policy scholars do not devote enough attention to the evolution of new sensitivities that may guide policymakers in complex environments. Consequently, they may miss new yardsticks for evaluating action, reaction, and counteraction which may be gradually evolving amongst political executives. One yardstick may be the preference for a policy which exhibits a direct and immediate relation with the results, making it clear that the outcome was caused by the policy at hand and not by another factor or actor. According to Lakoff (2016, p. 3), for example:

Many of Trump's policy proposals are framed in terms of direct causation. Immigrants are flooding in from Mexico - build a wall to stop them. For all the immigrants who have entered illegally, just deport them - even if there are 11 million of them working throughout the economy and living throughout the country. The cure for gun violence is to have a gun ready to directly shoot the shooter. To stop jobs from going to Asia where labor costs are lower and cheaper goods flood the market here, the solution is direct: put a huge tariff on those goods so they are more expensive than goods made here [...].

Other yardsticks may include the preference for a political game or conflict which can be broadcast live in all of its nuances, as well as the preference for a policy the (disproportionate) nature of which is directly linked to narratives, images, stories, and other ideational and symbolic carriers of meaning that societies tell themselves. A classic example is President Trump's disruptive approach to trade policy, as well as his manipulation of the migration debate (Greenhill 2018) during the Republican primaries, the presidential campaign, and in the run-up to the 2018 US mid-term elections.

Fourth, policy scholars do not pay enough attention to situations in which policymakers are designing policies with an eye to their target populations' mode of operation (or that of their political, social, economic, or military rivals). Consequently, they may miss attempts by political executives to design policies which, in terms of scale and/or perception, correspond to "walking on the edge" (i.e., brinkmanship). Doing so enables them to leave all policy options (e.g., behavioral responses of street-level police officers) open, sustain continued friction with 
their target populations or rivals, and try to induce the latter to retract. Policymakers may achieve this by applying repetitive overreactions: each policy move communicates a threshold which, if crossed, will trigger an overwhelming and drastic response. President Trump's tweets concerning the threats of nuclear war with North Korea and Iran provide a classic example of such a strategy. The responses of the respective leaders offer further examples. Deliberate, common, repeated, and routine investigatory police stops as an institutionalized practice rather than the haphazard activity of an individual officer (Epp 2014, p. 10) constitute another example.

Fifth, policy scholars do not sufficiently consider certain policy areas which manifest a startup (company) rhythm. The changing nature of the immigration crisis and the evolution of other cross-boundary threats provide classic examples of such areas. Consequently, scholars may miss the development of unorthodox policy solutions, which are intended to neutralize public fears and panic that undermine political executives' efforts to cope with the substance of such policy problems. Indeed, when policymakers devise policy solutions in contexts of panic and public fear, they must consider the mental state of the public, its emotional reserves, the prevailing narrative of the policy problems, the value orientation which is enshrined in each of the policy aims, and many more factors beyond objective cost-benefit calculation.

Sixth, policy scholars tend to implicitly assume that in any policy design, approval, and implementation process, the policymaker will, on the one hand, enter the political fray to approve the policy and implement it but, on the other, maintain his or her legitimacy for the next round of the policy cycle. This assumption is of the utmost importance in evaluating the proportionality of policy responses because the need to enter into political fights, while maintaining legitimacy for the next policy cycle, imposes restraints on policymakers' strategies, moderates their behavior, and shapes perceptions regarding proportionate behavior and policy response. This may not be the case when a policymaker is unaffected by any of these motivations, mainly seeking to push forward his or her preferred policies "at all costs"-i.e., viewing every political conflict as a zero-sum game-while ignoring political conventions and norms regarding "things that are not done." Employing such a strategy ensures that the politician will be at the center of controversy, thereby guaranteeing constant media coverage.

It seems that the common tendency among policy scholars to ignore modes of policy overreaction, let alone strategic overreaction, is closely connected with their propensity to focus on cases of status-quo policy arrangements, as well as moderate policy fluctuations. It is time to uncover the next layer of policy reality that lies underneath strong and wild fluctuations. We now turn our attention to a brief review of the existing literature and, thereafter, attempt to provide a useful way of organizing the reality of strategic policy overreaction alternatives for the reader.

\section{Taking Stock of Policy Overreaction Research}

Although research examining overreaction in politics and policy remains at an early stage, it is clearly developing along three paths. The first stream of research largely comprises psychological explanations identifying a pattern of overreaction thinking which systematically deviates from concepts of rational choice. This research mainly centers on how systematic cognitive biases in human decision-making (Kahneman 2011; Kahneman et al. 1982) inform anomalies in individual and collective behavior (Tversky and Kahneman 1974; Lichtenstein et al. 1978; Slovic 2007; Kahneman and Tversky 1973; Sunstein 2002; Sunstein and Zeckhauser 2010; Lichtenstein et al. 1982; Moore and Healy 2008; Patt and Zeckhauser 2000; Jones and 
Baumgartner 2005; Baumgartner et al. 2009). Its conceptual structure consists of micro-foundations (e.g., bounded-rationality) — key elements of human cognitive processes — which can thereafter be explicitly linked to collective activities in governments and at other societal level systems. The second stream, which is still in its infancy and, so far, remains conceptual in nature, concerns the independent effect of institutions (Peters et al. 2017). An elaboration of these explanations can be found elsewhere (Maor forthcoming). Institutional variables were also factored into models of rational behavior. For example, game theoretic models, in which officeholders face reelection and possess differing expertise, have found that electoral accountability motivates politicians to react disproportionately so that voters will view them as wellinformed. Such responses were found to be exacerbated by ideological polarization between the candidates (Bils 2018).

The third stream, also in its infancy and conceptual in nature, advances the idea that, at times, policy overreactions reflect deliberate choices which may successfully achieve the intended goals (Maor 2017a, 2017b, 2017c, 2017d, 2018a, 2018b, forthcoming). The analytical framework guiding the third stream, as well as this article, is the disproportionate policy perspective (Maor 2017c), which has four central tenets. First, under certain conditions, policymakers may face incentives to design and implement disproportionate policy options which, at times, may be successful in achieving a policy goal. Second, under certain conditions, policymakers may prioritize policy effectiveness over policy costs (policy overreaction or overinvestment) whereas, in other circumstances, a cost-conscious response may be chosen over an effective one (policy underreaction or underinvestment). Third, disproportionate policy options may be designed for use as signaling devices, context setters (e.g., enabling policymakers to resolve issues relating to the fragmentation of decision-making), or for purposes other than implementation on the ground. Fourth, policy overreaction will be pronounced when the emotional context of policy (e.g., hysteria) may be equally, if not more, important than the substantive nature of the policy problem (e.g., in cases of suspected contagious disease).

Strategic explanations of policy overreaction view decision-makers as boundedly rational individuals and bring to the fore the assumptions underlying bounded rationality, that is, the existence of variation amongst individuals and contexts in decision-making processes and outcomes (Simon 1985). Because individuals differ in their motivations and opportunities to carefully process information, and because contexts differ in their complexity, individuals need not be consistent decision-makers (Lodge and Taber, 2000), as rational choice theory assumes (e.g., Simon 1995). In policy contexts, this insight implies that decision-makers do not need to place efficient goal attainment center stage in every decision they take. Some individuals, operating within particular contexts, can therefore overcome (the "efficient goal attainment") bias (Lau et al. 2008) and make "rational"—read "reasonable" or "good enough" — policy overreaction decisions.

According to Maor (2018b), elected officials may be motivated to overreact in order, for example, to restore confidence in policy within a matter of days during crises that generate panic and popular fears; to produce an overwhelming effect as an act of leadership; to shift the contours of public debate abruptly; to create and secure a historical legacy; and to apply a grand strategy to policy problems and the public interest, especially on issues around which voters share a common preference, such as security and economic performance (Maor 2017a, 2017b, 2018b). They may also be inclined to overreact when the very identity of their state is at stake, as in the case of decisions that are both transformative and irrevocable; when a policy problem cannot be disaggregated and therefore needs to be addressed on a large scale; and when policymak- 
ers expect that positive feedback on policy will be overwhelmed by negative feedback (Maor $2018 \mathrm{~b}$, forthcoming). In international politics and other areas with deficient verification and enforcement mechanisms, policymakers may be motivated to overreact in order to make intentions clear to the other side, thereby strengthening coercive diplomacy and avoiding unnecessary wars (Jervis 2017).

Strategic explanations also posit that when there is relative uncertainty regarding the appropriate policy choice to be pursued, political executives have more room to bridge disparities between voters' expectations and governments' actual policy capacity, pander to public opinion, appear informed to voters, and signal extremity (e.g., Bils 2018; Canes-Wrone et al. 2001; Maor 2014a, 2017a, forthcoming; Rabinowitz and Macdonald 1989)3. This, in turn, may incentivize political executives to implement populist or extreme policies. Under such circumstances, the term 'policy overreaction' maintains its negative meaning in relation to what could happen (i.e., inefficient policy). At the same time, however, it also acquires a positive meaning from the perspective of executive politicians: this is due to the political benefits that they may gain from policy overreaction (e.g., when the public views overreaction favorably). In such cases, because policy is not evaluated in a vacuum but rather vis-à-vis an information set comprised of cost-benefit analyses, situation evaluations and risk assessments, it may be possible to identify policy overreaction before the policy is implemented and in relation to what could happen.

The discussion so far brings to the fore the fact that not all policy overreactions have the same root cause, and, therefore, every policy overreaction differs in significant ways-especially in the modern era of active media involvement in policy processes (e.g., Wolfe et al. 2013; Montpetit 2016). At the same time, however, the discussion highlights a distinct category of such policy responses-comprised of strategic policy overreactions-and advances the argument that, from the perspective of political executives, these overreactions should be viewed as risky policy investments rather than policy errors. Against this background, we apply the disproportionate policy perspective to gauge modes of strategic policy overreaction. This is a risky task because without information about the expected value of strategic policy overreaction for policymakers, we have no way of knowing whether such a policy choice arises from a political executive's mental illness (e.g., Sachs and Lee 2018), biased judgment, or a political calculus. In addition, "people lack privileged access to their own motives and calculations, which means that people develop retrospective explanations for their own behavior" (Jervis 2017, p. 5). Policymakers are therefore unlikely to admit that they deliberately designed policy overreaction alternatives. Further, in current political and policy sciences, the trade-off between rigor and relevance favors rigor, resulting in a decrease in relevance. To bridge this gap, the next section tips the balance toward relevance by ascertaining modes of policy overreaction from the generic, empirical characteristics of disproportionate policy response.

We do not claim that the examples presented herein are strategic policy overreactions (although we encourage scholars to examine this question), nor that the proposed taxonomy includes all types of strategic overreactions. Our modest claim is that the taxonomy explores what are perhaps the four most important categories of the phenomenon under investigation and this, in turn, enables us to tap into the menu for strategic policy overreaction available to political executives who wish to pursue such policy responses.

3 - Given the difficulty involved in measuring the public's preferred levels of policy, scholars should be careful before jumping to conclusions regarding the impact which public opinion may have on strategic policy overreaction. "It may be, after all, that politicians change policy in response to changing opinion but that the level of policy under- or overshoots what the public actually wants" (Wlezien 2015, p. 143). 


\section{Modes of Strategic Policy Overreaction}

Two dimensions of policy overreaction are both empirically observable and measurable and can therefore be used for ex ante policy advice as well as ex post policy evaluation: (i) the scale of the policy response insofar as objective costs and benefits are concerned; and, (ii) how the general public, or (large) segments thereof, perceives the policy response. The former dimension represents apolitical (i.e., value neutral), unbiased, quantitative expectations or assessments of policy costs and benefits. It thus provides a measurement of (expected or actual) policy performance in an objective manner, or as practically as possible, in line with the rationalistic policy evaluation tradition (e.g., Hawkesworth 1988; Lynn 1999; Mabry 2002; see also Sunstein 2018). Large scale overreaction implies that social costs considerably outweigh social benefits. The second dimension, the (expected or actual) perception of policy response, roughly corresponds to the concept of policy image (Baumgartner and Jones 1993), yet here it reflects different conceptions about the proportionality of the policy. It is obviously context-sensitive, a biased evaluation which is influenced by politics and power (McConnell 2010; Bovens and 't Hart 1996) and accords with the argumentative policy evaluation tradition (e.g., Fischer and Forester 1993; Fischer 1998; Yanow 2000). Among the reasons for variations in the second dimension is the fact that some policy overreactions do not register on the media radar (e.g., due to state secrecy laws) or initiate any kind of reaction from the political elite and public opinion.

Based on these dimensions, and focusing principally on states rather than subnational governments, we have identified four categories of strategic policy overreaction-depicted in Table 1 - that reflect differences in the nature of proposed or implemented policy.

Table 1. Strategic Policy Overreaction Alternatives

Scale of Policy Overreaction

Large Small

Public Perceptions

of Policy

I

Overreaction

Proportionate/
Underreaction
Zero-tolerance/Unlimited policies

(e.g., Zero-tolerance border enforcement policy; Zero-tolerance crime policy; Open border policy)

IV

\section{Covert overreaction}

(e.g., state torture and mass-sur-

veillance programs)
II

\section{Explicit overreaction rhetoric \& doctrine}

Precision overreaction

(e.g., targeted killings; police stop and search policy)

III

The first category includes zero-tolerance policies as well as unlimited policies. When implemented on the ground, the totality of such policies' aims requires (i) significant committed resources available for use with discretion, and/or (ii) insensitivity to the heterogeneity of the target 
populations and/or implementing agencies. Heightened public visibility of the amount of committed resources, the extent of delegated responsibilities across numerous agencies, the drastic weakening/bolstering of individual rights and freedoms (in zero-tolerance and unlimited policies, respectively), as well as the huge scale of policy implementation (which is often reinforced by an ongoing predominance of negative news regarding things that went wrong) govern the perceptions of these policies as overreactions. Added to this are the strong emotional responses that such policies elicit among members of the general public. Such emotions, evoked by the effects of zero-tolerance and unlimited policies on target populations (e.g., the plight of migrants, especially young children) and segments of society opposing such policies, further solidify the perception of these policies as overreaction. Further, the emotional facets of zerotolerance and unlimited policies provide grounds for the operation of emotional entrepreneurs who attempt to either increase (up-regulate) or decrease (down-regulate) a particular emotion, such as fear or anger, or to change the type of emotion (e.g., transforming anxiety into anger) (Maor and Gross 2015).

In the US, classic examples of zero-tolerance policies include the Morgan Act, the US Crime Act, and President Trump's zero-tolerance border enforcement policy. In the UK, examples of zero-tolerance policies include the Crime and Disorder Act, Crime Reduction Partnership, and the Home Office national objectives (Garland 1996; Gilling 2001). In Israel, an example is the zero-tolerance policy utilized during 2017 on the Gaza-Israel border. Classic examples of unlimited policy include Angela Merkel's open border refugee policy, as well as the Labour Government's 2004 decision to accord citizens from ten former Soviet bloc countries that have joined the EU what were, in effect, unrestricted rights of migration to the United Kingdom.

The second category, which includes explicit policy overreaction rhetoric and doctrines, is characterized by small scale overreaction accompanied by public perception as overreaction, whereas the third category includes implicit policy overreaction rhetoric and doctrines that are characterized by small scale overreaction and perceived by the public as proportionate or underreaction. Let us first explain the meaning of policy overreaction rhetoric and doctrines. Policy overreaction doctrine refers to "a coherent set of policy principles which presents an 'all or nothing' policy commitment in pursuit of a policy goal no matter what the costs are" (Maor 2018a, p. 52). At the heart of a policy overreaction doctrine lie principles for the use of overwhelming government force in order to achieve a decisive and quick policy outcome in a particular policy domain. A policy overreaction doctrine rejects a gradualist approach to the use of government power, instead seeking to implement-or to communicate to target populations-an all-ornothing policy approach that leaves no room for compromise and therefore ties the hands of policymakers and raises the political costs of any use of government force. A policy overreaction doctrine communicates to the target populations and the general public that, on this particular policy issue, effectiveness takes precedence over cost containment considerations (Maor 2017a, 2018a).

Policy overreaction rhetoric, a sub-set of policy overreaction doctrine, refers to "arguments that policymakers employ to reach and persuade the target populations of their 'all or nothing' policy commitment to achieve their policy goal, no matter what the costs are" (Maor 2018a, p. 53). It reflects a single constraint-to achieve a policy goal regardless of the costs-which is endogenously imposed on policymakers by way of the all-or-nothing public commitment they make and will be very costly to maintain in terms of the nation's welfare, should the need arise (Maor 2018a).

In both the explicit and implicit categories, it is clear to the recipient what threats and/or 
promises are being communicated, as well as the intended message. In addition, as statements of intent, both strategies involve costs that are incurred not when the statements are issued, but only later, if the actors do not live up to them. However, only in the explicit strategy is it clear to the recipient what others (e.g., the general public, other organizations, countries, and so on) will think is being communicated. This is due to the heightened public visibility inherent in the explicit form, which often involves emotional, dramatic, coarse, cruel, and other types of inappropriate and unconventional language-breaching every known custom of diplomacyin order to impress the policymakers' resolve upon their audiences. Such language is often used to demonize marginalized populations and ignite moral panic (e.g., global Islamophobia, single mothers on welfare, and gay rights).

As the language used becomes more aggressive and excessive (e.g., threats to use brute force), it is increasingly likely that the audience will be "captured," that is, the target will be able to determine what policymakers are trying to say and will be controlled. The physical and concrete character of the intended policy instrument is unlikely to generate ambiguities and uncertainties, leaving no cognitive gaps and dead ends for perceivers and observers. The more physical and concrete (rather than abstract) the policy tools which actors propose to employ excessively when the time comes, and the more authoritative and commanding the threats or promises, the less vulnerable these threats or promises will be to narrative-grounded evaluations by 'experts' and other commentators which contradict the statements of intent. Statements that include a creative aspect or image of an excessive nature - well-crafted in terms of words, images, political tone (Hart et al. 2013), and the values it conveys - are likely to reinforce the message. Thus, when employing the explicit strategy, the totality of the message ensures that the initiators of overreaction rhetoric and doctrines, the receiver, and all observers interpret it in the same way. The difference between the two strategies lies therefore in the channels of communication employed. Whereas the explicit strategy is publicly communicated, the implicit one is imparted through secret or informal channels, either directly or via third parties, unofficial/official mediators, and so on. Finally, with the rise of social media, the costs of employing the explicit strategy have declined dramatically.

The second category, which includes explicit overreaction rhetoric and doctrines, also encompasses precision overreaction, such as targeted killings using more or less invasive coercive measures, as well as police stop and search policies. Regardless of whether this strategy is overused, it is: (i) relatively small scale and, in the case of lethal drone technology (i.e., human-controlled robotic aerial systems capable of inflicting human death), involves lower costs compared to the alternatives, such as the use of aircrafts, cruise missiles, and special operations forces (Buchanan and Keohane 2015, 16); and, (ii) perceived by the public as an overreaction. The latter may derive from ambiguity in the distinction between legitimate and illegitimate (human) targets, leading to errors and abuse (e.g., when officers act on implicit stereotypes regarding suspicious appearances); collateral damage to civilians and property in the case of lethal drones, as well as violations of sovereignty resulting from unauthorized entry into another state's territory; an absence of legal accountability (e.g., the lack of regulation and compliance with the laws of war in the case of lethal drones); mismanagement and lack of oversight; or other moral or legal aspects (e.g., Alford 2017; Weitzer and Tuch 2006). Whereas some of these aspects are immediately and publicly visible, others, such as user errors and abuse, may be uncovered following reports by "whistle-blowers," survivors, observers, researchers, and the like (Buchanan and Keohane 2015, 16).

The fourth category-large scale overreaction and public perceptions of policy response as pro- 
portionate or underreaction-is covert overreaction. The costs of such policy involve maintaining sites for covert policy (e.g., CIA black sites or surveillance sites), developing and employing equipment, instruments, and advanced technology, developing modes of operation, employing and training highly qualified personnel, concealing the aforementioned sites and operations, and so on (e.g., Sands 2008). It may be possible to ensure that the public perceives such a response as proportionate or an underreaction by using administrative restrictions on the visibility of the policy domain, on public accountability, and on the voicing of dissent by employees, as well as by releasing inaccurate information concerning the effectiveness of the policy at hand to Congress, government departments, and the media.

An example is the Central Intelligence Agency's (CIA) torture program which operated during 2001-2006 on a global scale (e.g., the American prison complex at Guantánamo Bay, Cuba). The CIA authorized the use of enhanced interrogation techniques (EITs) (e.g., prolonged sleep and sensory deprivation, enforced nudity, and painful body positions) following the $9 / 11$ attacks, despite the fact that the United Nations considers EITs torture. There was ample evidence regarding the unreliability and questionable legality of coerced confessions (Iacopino et al. 2011, p. 34), and even the CIA's Counterintelligence Interrogation (KUBARK) manual observed that direct physical brutality creates only resentment, hostility, and further defiance rather than yielding valuable information (CIA 1963). Unsurprisingly, the Senate Select Committee on Intelligence (2014) concluded that the EITs employed in the program were an ineffective means of acquiring intelligence or gaining cooperation from detainees. It also concluded that the CIA repeatedly provided inaccurate information to the Department of Justice, impeding a proper legal analysis of the CIA's Detention and Interrogation Program, and that it actively avoided or hindered congressional oversight, effective White House oversight, as well as supervision by the Office of the CIA Inspector General (Senate Select Committee on Intelligence 2014).

The aforementioned taxonomy brings to the fore four distinct empirical categories since none of these policy responses falls into more than one category. Building on this sharp distinction, attention now turns to the explanatory and predictive resources which scholars can extract from the aforementioned empirical construction.

\section{Policy Overreaction as Risky Policy Investment: Hypotheses}

The taxonomy advanced here produces a set of hypotheses about differing patterns of the policy process and governance that may be connected to modes of strategic policy overreaction. The common thread running through the following hypotheses is the focus on interactions that occur over time between strategic policy overreaction and surrounding actors, events, contexts, and outcomes, and the benefits that political executives reap from such policy responses.

Scholars may hypothesize, for example, that zero-tolerance policies, as well as unlimited ones, involve a high level of concern amongst policymakers regarding the relative status of their state (i.e., decision-makers are significantly dissatisfied with their "standing, or rank, in a status community" [Renshon 2017, p. 4]) and therefore the excessive nature of the policy response. This hypothesis is based on the premise that attempts to advance a state's status and prestige are costly and risky, yet "if they succeed, they can bring rewards all out of proportion to [those] costs by influencing the psychological environment and policies of other decisionmakers" (Jervis 1989, p. 8). Scholars may also hypothesize that zero-tolerance policies, as well as unlimited ones, involve broad consensus among the general public and members of the political elite regarding the nature of the policy problem and the preferable solution; a low level of compromise (i.e., little government effort to accommodate minority interests); a weak role for 
experts due to the negligible position accorded to scientific and technical information in the policy process; a weak role for senior civil servants due to their demands that the heterogeneity of the target population and/or implementing agencies be considered (read, their demands to offer policy advice solely according to cost-benefit analysis); a rise of formidable bureaucratic machinery in order to implement the policy at hand; and an emergence of agents that are incentivized to publicly produce and communicate information about the costs and benefits of the policy.

Policy scholars may also hypothesize that covert overreaction by states may accord a weak role for senior civil servants who primarily wish to avoid violation of international and/or domestic laws but an important role for scientific and technical information in the policy process, meaning a dominant role for experts. Covert overreaction may also entail conscious attempts by political executives to insulate government actions from domestic politics by undertaking selective release of information and careful media presentation; a wide gap between publicly expressed preferences by government agencies and actual behavior; a subordination of moral considerations to operational ones; and a tendency for whistle-blowing by policy formulators and implementers who are forced to live in silence while aware of the true nature of government actions and deeds to which they have been party.

Scholars may hypothesize that explicit overreaction rhetoric involves an informal, direct, and provocative (even uncivil) communication style; a clear-cut threat/promise; and a reinforced dichotomous mental map by government agencies, using positive self-representation and negative other-representation. It may also entail attempts to create categories, to legitimize or delegitimize actors and actions, and to create a sense of national unity. By contrast, one may hypothesize that implicit overreaction rhetoric involves a much more formal communication style (although conveyed through informal channels) and a clear-cut threat/promise.

Furthermore, scholars may hypothesize that precision overreaction by states involves either a series of interlocking "gates" that guide policy decisions at the highest level of government but allows higher levels of discretion for policymakers, or no "gates" at all (i.e., decisions to stop and search people based on 'suspicions' [read, intuitions] felt by street-level bureaucrats regarding a person's appearance and behavior, or decisions to stop and search without 'reasonable suspicion', as in the 2019 attempt by the UK government to tackle knife crime in England and Wales). In both cases, decisions are largely based on interpretive judgments and evidence of a primarily indirect nature rather than on accurate and up-to-date information and intelligence. This, in turn, allows higher levels of discretion and reasonable latitude for policymakers and/or implementers to undermine individual human rights while executing the tasks at hand, on the one hand, and, on the other, increases the vulnerability of operative decisions to ambiguities in legal interpretations and to poor handling and abuse.

Although these categories reflect different policy alternatives, some could be used in unison. Scholars may hypothesize that there are at least four practical possibilities: zero-tolerance policy combined with explicit overreaction rhetoric and doctrine; unlimited policy combined with explicit overreaction rhetoric and doctrine; explicit overreaction rhetoric and doctrine combined with implicit overreaction rhetoric and doctrine; and precision overreaction combined with explicit overreaction rhetoric and doctrine. In addition, there are incentives to free-ride and let the overreacting agency bear the costs and risks. Different policy overreactions can lead to different patterns of free riding. All the aforementioned propositions are testable hypotheses that can be addressed comparatively. 
Policy overreaction is assessed by carefully evaluating four components: (i) the policy details and the behavior of its implementing agencies; (ii) the context and circumstances; (iii) the target audience (e.g., capacities, ethics, and so on); and (iv) the policy results. Alternatively, De Francesco and Maggetti (2018) developed a framework to conceptualize, operationalize, and assess disproportionate policy responses from a cross-sectional perspective, creating a series of indexes to measure policy overreaction (as well as underreaction) among the EU member states that experienced the 2007-2008 banking crisis. However, to demonstrate that policy overreactions are deliberately chosen, scholars should employ process tracing as well as elite interviews and content analysis of policymakers' rhetoric and doctrines, especially when the policy enacted deviates considerably from policy advice based on cost-benefit analysis. Scholars may also adopt a social constructionist perspective to explain how policymakers engage in competition and meaning wars (Maor 2017d) over the criteria for judging the proportionality of policy responses. They may analyze the content of policymakers' press releases, contrasting it with that of media coverage, to reveal how policy criteria regarding the proportionality of outcomes emerge and are challenged, influenced, and embraced by policymakers, target groups, and the general public.

\section{Conclusions}

Over the last few years, and especially with the election of President Trump, the phenomenon of policy overreaction has become increasingly important for scholars and practitioners seeking to understand dramatic and highly unconventional policy moves at the levels of rhetoric, doctrine, and action on the ground. Traditionally, this has been explained by questioning leaders' mental stability or focusing on cognitive biases and opportunistic tendencies. This article presents an alternative view, and hopefully a new intellectual path, which "detoxifies" the phenomenon under investigation by considering some policy overreactions-from the perspective of political executives - as strategic and risky policy investment, not necessarily a policy mistake. This view naturally spawns a thicket of ethical problems, which are beyond the scope of the present discussion.

Although a taxonomic approach to policy classification raises problems of its own (Smith 2002), it can advance our practical understanding by shedding light on clusters of policy responses which are employed to address a great variety of policy problems. Using such an approach, this article distinguishes policy overreactions according to their scale in terms of objective costbenefits, as well as perceptions of them, which range from over- to underreaction. Among the core implications of the taxonomy advanced here are: (i) substantial empirical heterogeneity among policy overreaction responses which could be viewed as alternative strategies available to policymakers who wish to overreact; and, (ii) distinct types of overreaction which may be associated with well-defined modes of politics and governance.

Political and policy scientists have already recognized that, in some cases, the success or failure of policies rests ultimately with policy perceptions, not substance, while in other instances substance triumphs over image, or a combination thereof is at play (McConnell 2010) ${ }^{4}$. Given this recognition, perhaps the time has come to recognize that strategic policy overreactions are not just important, but researchable. Rather than stacking up more demonstrations of traditional public policy theories, scholars who are willing to move outside their comfort zones, as well as

4 - Policy image also plays an important role in the case of policy bubbles (Maor 2014b, 2016; 2018c; Jones et al. 2014). 
ambitious Ph.D. students, should attempt to puncture the idea that policy overreactions arise solely from policy mistakes, while aiming to answer a much broader question: Is the repertoire of public policy alternatives in the twenty-first century, insofar as policy proportionality is concerned, different to that of the 1980s and 1990s? Secondly, if so, is this due to changes in state capacity to overreact, developments in the "taken-for-granted" status of institutionalized expectations regarding desirable conduct, or changes in politicians' style of conduct? The rise of populist politics, narcissistic leaders, digital demagogues, as well as the crisis of democracy (Wolfe 2018; Fuchs 2018; Levitsky and Ziblatt 2018; Norris and Inglehart 2018; Mounk 2018) provide ample data in this regard. To bring data to bear on this question, scholars and students should contextualize policy costs and benefits from the policymakers' perspective, in addition employing process tracing methods, interviews, and other methodologies to gauge processes that involve the design and implementation of strategic policy overreactions. Strategic policy overreactions, we argue here, are costly and risky in terms of both substance and public perception but, if successful, can bring political executives considerable rewards.

\section{Bibliography}

Alford, R. (2017). Permanent State of Emergency: Unchecked Executive Power and the Demise of the Rule of Law. Montreal: McGill-Queen's University Press.

Baumgartner, F. R., Breunig, C., Green-Pedersen, C., Jones, B. D., Mortensen, P. B., Nuytemans, M., \& Walgrave, S. (2009). Punctuated Equilibrium in Comparative Perspective. American Journal of Political Science, 53(3), 603-620.

Baumgartner, F. R., \& Jones, B. D. (1993). Agendas and Instability in American Politics. Chicago: Chicago University Press.

Bils, P. (2018). Disproportionate Policy Response and Executive Expertise. Unpublished Working Paper. Retrieved from http://peterbils.com/wp-content/uploads/2018/09/disproportionate-policy-responses-6.pdf (15.11.2018)

Bovens, M., \& 't Hart, P. (1996). Understanding Policy Fiascos. New Brunswick, Transaction.

Buchanan, A. \& Keohane, R. O. (2015). Toward a Drone Accountability Regime. Ethics \& International Affairs, 29(1), 15-37.

Canes-Wrone, B., Herron, M.C., \& Shotts, K.W. (2001). Leadership and Pandering: A Theory of Executive Policymaking. American Journal of Political Science, 45, 532-550.

Central Intelligence Agency (CIA). 1963. KUBARK Counterintelligence Interrogation. Retrieved from http://nsarchive.gwu.edu/NSAEBB/NSAEBB122/CIA\%20Kubark\%201-60.pdf (15.11.2018).

Chong, D. (2013). Degrees of Rationality in Politics. In (Ed.), The Oxford Handbook of Political Psychology. Oxford: Oxford University Press.

De Francesco, F. \& Maggetti, M. (2018). Assessing Disproportionality: Indexes of Policy Responses to the 2007-2008 Banking Crisis. Policy Sciences, 51(1), 17-38.

Duggan, J. \& Martinelli, C.S. (2015). Electoral accountability and responsive democracy. GMU Working Paper in Economics No. 15-31. Retrieved from http://dx.doi.org/10.2139/ssrn.2606481 (15.11.2018). 
Epp, C. E. (2014). Pulled Over: How Police Stops Define Race and Citizenship. Chicago: Chicago University Press.

Fischer, F. (1998). Beyond Empiricism: Policy Inquiry in Postpositivist Perspective. Policy Studies Journal, 26, 129-46.

Fischer, F. \& Forester, J, (1993). The Argumentative Turn in Policy Analysis and Planning. Durham, NC: Duke University Press.

Fuchs, C. (2018). Authoritarian Capitalism in the Age of Trump and Twitter. London: Pluto Press.

Garland, D. (1996). The Limits of the Sovereign State: Strategies of Crime Control in Contemporary Societies. British Journal of Criminology, 36(4), 445-71.

Greenhill, K. M. (2018). How Trump Manipulates the Migration Debate. The Use and Abuse of Extra-Factual Information. Foreign Affairs. Snapshot, July 5.

Gilling, D. (2001). Community Safety and Social Policy. European Journal on Criminal Policy and Research, 9, 381-400.

Hart, R.P., Childers, J.P. \& Lind C.J. (2013). Political Tone: How Leaders Talk and Why. Chicago: University of Chicago Press.

Hawkesworth, M. E. (1988). Theoretical Issues in Policy Analysis. Albany: State University of New York Press.

Hogwood, B. W. \& Peters, B. G. (1985). The Pathology of Public Policy. Oxford: Clarendon Press.

Iacopine, V., Allen, S. A., \& Keller, A. S. (2011). Bad Science Used to Support Torture and Human Experimentation. Science, 331, 34-5.

Jervis, R. (1989). The Logic of Image in International Relations. New York: Columbia University Press.

Jervis, R. (2017). How Statesmen Think: The Psychology of International Politics. Princeton: Princeton University Press.

Jones, B. D. \& Baumgartner, F. R. (2005). The Politics of Attention: How Government Prioritizes Problems. Chicago: University of Chicago Press.

Jones, B.D., Thomas III, H.F., \& Wolfe, M. (2014). Policy Bubbles. Policy Studies Journal, 42, 146-171.

Kahneman, D. (2011). Thinking, Fast and Slow. New York: Farrar, Straus, and Giroux.

Kahneman, D., Slovic, P., \& Tversky, A. (Eds.) (1982). Judgment under Uncertainty: Heuristics and Biases. New York: Cambridge University Press.

Kahneman, D. \& Tversky, A. (1973). On the Psychology of Prediction. Psychological Review, 80, 237251.

Lakoff, G. (2016). Understanding Trump. Book excerpt. Retrieved from https://press.uchicago.edu/ books/excerpt/2016/lakoff_trump.html (15.11.2018)

Lau. R.R., Anderson, D.J., \& Redlawsk, D.P. (2008). An Exploration of Correct Voting in Recent U.S. Presidential Elections. American Journal of Political Science, 52, 395-411.

Levitsky, S. \& Ziblatt, D. (2018). How Democracies Die. New York: Crown.

Lichtenstein, S., Fischhoff, B., \& Phillips, L. D. (1982). Calibration of Probabilities: The State of the Art in 1980. In D. Kahneman, P. Slovic, \& A. Tversky (Eds.), Judgment under Uncertainty: Heuristics and Biases (pp. 306-333). Cambridge: Cambridge University Press. 
Lichtenstein, S., Slovic, P., Fischhoff, B., Layman, M., \& Combs, B. (1978). Judged Frequency of Lethal Events. Journal of Experimental Psychology: Human Learning and Memory, 4, 551-578.

Lodge, M. \& Taber, C. (2000). Three Steps toward a Theory of Motivated Political Reasoning. In Lupia, A., McCubbins, M., \& Popkin, S. (Eds.), Elements of Reason: Cognition, Choice, and the Bounds of Rationality. New York: Cambridge University Press.

Lynn, L. E. (1999). A Place at the Table: Policy Analysis, Its Postpositive Critics and the Future of Practice. Journal of Policy Analysis and Management, 18, 411- 24.

Mabry, L. (2002). Postmodern Evaluation-or Not? American Journal of Evaluation, 23, 141-57.

Maor, M. (2012). Policy Overreaction. Journal of Public Policy, 32, 231-259.

Maor, M. (2014a). Policy Persistence, Risk Estimation and Policy Underreaction. Policy Sciences, 47, 425-443.

Maor, M. (2014b). Policy Bubbles: Policy Overreaction and Positive Feedback. Governance, 27, 469487.

Maor, M. (2016). Emotion-Driven Negative Policy Bubbles. Policy Sciences, 49, 191- 210.

Maor, M. (2017a). The Implications of the Emerging Disproportionate Policy Perspective for the New Policy Design Studies. Policy Sciences, 50, 383-398.

Maor, M. (2017b). Policy Overreaction Doctrine: From Ideal-Type to Context-Sensitive Solution in Times of Crisis. In Howlett, M. \& Mukherjee, I. (Eds.), Handbook of Policy Formulation (pp. 539-553). Cheltenham: Edward Elgar.

Maor, M. (2017c). Policy Entrepreneurs in Policy Valuation Processes: The Case of the Coalition for Environmentally Responsible Economies. Environment and Planning C: Government and Policy, 35, 1401-1417.

Maor, M. (2017d). Disproportionate Policy Response. In The Oxford Research Encyclopedia of Politics. DOI:10.1093/acrefore/9780190228637.013.168

Maor, M. (2018a). Rhetoric and Doctrines of Policy Over- and Underreactions in Times of Crisis. Policy \& Politics, 46, 47-63.

Maor, M. (2018b). Disproportionate Policy Response by Design: Towards a Conceptual Turn. Paper presented at the ECPR General Conference at the University of Hamburg, 22-25 August.

Maor, M. (2018c). A Social Network Perspective on the Interaction Between Policy Bubbles. Working Paper. Jerusalem: Department of Political Science, The Hebrew University.

Maor, M. (Forthcoming). Overreaction and Bubbles in Politics and Policy. In Mintz, A. \& Terris, L. (Eds.), Oxford Handbook on Behavioral Political Science. Oxford: Oxford University Press.

Maor, M. \& Gross, J. (2015). Emotion Regulation by Emotional Entrepreneurs: Implications for Political Science and International Relations. Paper presented at the 73rd Annual Conference of the Midwest Political Science Association, April 16-19, 2015, Chicago.

Maor, M., Tosun, J., \& Jordan, A. (2017). Proportionate and Disproportionate Policy Responses to Climate Change: Core Concepts and Empirical Applications. Journal of Environmental Policy \& Planning, 19, 599-611.

Marsh, D., 't Hart, P., \& Tindall, K. (2010). Celebrity Politics: The Politics of Late Modernity. Political Studies Review, 8(3), 322-340. 
McConnell, A. (2010). Policy Success, Policy Failure and Grey Areas In-Between. Journal of Public Policy, 30(3), 345-362.

Montpetit, É. (2016). In Defense of Pluralism: Policy Disagreement and Its Media Coverage. Cambridge: Cambridge University Press.

Moore, D. A. \& Healy, P. J. (2008). The Trouble with Overconfidence. Psychological Review, 115(2), 502-517.

Moran, M. (2003). The British Regulatory State: High Modernism and Hyper Innovation. Oxford: Oxford University Press.

Mounk, Y. (2018). The People vs. Democracy: Why Our Freedom Is in Danger and How to Save It. Cambridge, Mass.: Harvard University Press.

Norris, P. \& Inlehart, R. (2018). Cultural Backlash: Trump, Brexit, and Authoritarian Populism. Cambridge: Cambridge University Press.

Patt, A. \& Zeckhauser, R. (2000). Action Bias and Environmental Decisions. Journal of Risk and Uncertainty, 21(1), 45-72.

Peters, G., Jordan, A., \& Tosun, J. (2017). Over-reaction and Under-reaction in Climate Policy: An Institutional Analysis. Journal of Environmental Policy \& Planning, 19(6), 612-624.

Rabinowitz, G., \& Macdonald, S. E. (1989) A Directional Theory of Issue Voting. American Political Science Review, 83(1), 93-121.

Renshon, J. (2017). Fighting for Status: Hierarchy and Conflict in World Politics. Princeton: Princeton University Press.

Sachs, J. D. \& Lee, B. X. (2018). Trump's Psychopathology is Getting Worse. Project-Syndicate, July 3. Retrieved from https://www.project-syndicate.org/commentary/trump-psychological-problemsgetting-worse-by-jeffrey-d-sachs-and-bandy-x-lee-2018-07.

Sands, P. (2008). Torture Team: Rumsfeld's Memo and the Betrayal of American Values. London: Palgrave Macmillan.

Schneider. A. L., Ingram, H., \& de Leon, P. (2014) Democratic Policy Design: Social Construction of Target Populations. In Sabatier, P. A. \& Weible, C. M. (Eds.), Theories of the Policy Process (pp. 105150). Boulder, CO: Westview Press.

Senate Select Committee on Intelligence. 2014. The Senate Intelligence Committee Report on Torture: Committee Study of the Central Intelligence Agency's Detention and Interrogation Program. Retrieved from http://fas.org/irp/congress/2014_rpt/ssci-rdi.pdf

Simon, H. A. (1985). Human Nature in Politics: The Dialogue of Psychology with Political Science. American Political Science Review, 79(2), 293-304.

Simon, H. A. (1995). Rationality in Political Behavior. In P. K. Moser (Ed.), Rationality in Action: Contemporary Approaches (pp. 189-204). New York: Cambridge University Press.

Slovic, P. (2007). If I Look at the Mass I Will Never Act: Psychic Numbing and Genocide. Judgment and Decision Making, 2(2), 79-95.

Smith, K. B. (2002). Typologies, Taxonomies, and the Benefits of Policy Classification. Policy Studies Journal, 30(3), 379-395.

Street, J. (2018). What is Donald Trump? Forms of 'Celebrity' in Celebrity Politics. Political Studies Review. doi.org/10.1177/1478929918772995. 
Sunstein, C. R. (2002). Probability Neglect: Emotions, Worst Cases and Law. Yale Law Journal, 112, 61-107.

Sunstein, C. R. (2018). The Cost-Benefit Revolution. Cambridge, Mass.: MIT Press.

Sunstein, C. R. \& Zeckhauser, R. J. (2010). Dreadful Possibilities, Neglected Probabilities. In E. Michel-Kerjan \& P. Slovic (Eds.), The Irrational Economist: Making Decisions in a Dangerous World (pp. 116-123). New York: Perseus Books.

Tversky. A. \& Kahneman, D. (1974). Availability: A Heuristic for Judging Frequency and Probability. Cognitive Psychology, 5, 207-232.

Walker, S. G. \& Malici, A. (2011). U.S. Presidents and Foreign Policy Mistakes. Stanford: Stanford University Press.

Weitzer, R. \& Tuch, S. A. (2006). Race and Policing in America: Conflict and Reform. Cambridge, N.Y.: Cambridge University Press.

Wheeler, M. (2013). Celebrity Politics: Image and Identity in Contemporary Political Communication. Cambridge: Polity Press.

Wlezien, C. (2015). V. O. Key, Jr., Public Opinion and American Democracy. In S. J. Balla, M. Lodge, \& E. C. Page (Eds.), The Oxford Handbook of Classics in Public Policy and Administration (pp. 137-153). Oxford: Oxford University Press.

Wolfe, A. (2018). The Politics of Petulance: America in an Age of Immaturity. Chicago: Chicago University Press.

Wolfe, M., Jones, B. D., \& Baumgartner, F. R. (2013). A Failure to Communicate: Agenda Setting in Media and Policy Studies. Political Communication, 30(2), 175-192.

Wood, M., Corbett, J., \& Flinders, M. (2016). Just Like Us: Everyday Celebrity Politicians and the Pursuit of Popularity in an Age of Anti-Politics. British Journal of Politics and International Relations, 18(3), 581-598.

Yanow, D. (2000). Conducting Interpretative Policy Analysis. Newbury Park, California: Sage. 